\title{
MENELAAH TEORI DISTRIBUTIVE JUSTICE PADA ISU SISTEM MANAJEMEN KESEHATAN DAN KESELAMATAN KERJA
}

Oleh :

Santo Arimartin

\section{Santo.arimartin@gmail.com}

\begin{abstract}
ABSTRAK
Terkait dengan perkembangan jaman, lahan-lahan persawahan sudah mulai berubah menjadi pabrik-pabrik. Sejalan dengan perkembangan teknologi Negara agraris mulai berubah menjadi Negara industri dan membangun banyak perusahaan. Sumber Daya Manusia mengambil peranan penting dalam pertumbuhan suatu perusahaahan.oleh karena itu, kinerja SDM harus selalu dalam posisi yang maksimal dan terjamin demi mendapatkan keuntungan. Jaminan yang perlu diperhatikan terkait dengan kesehatan dan keselamatan SDM tersebut. Jaminan kesehatan dan keselamatan ini tertuang kedalam suatu sistem manajemen yang mengatur tentang bagaimana jaminan tersebut dapat menjaga semua karyawan disuatu perusahaan mendapat hak-haknya terkait kesehatan dan keselamatan kerja. Salah satu bentuk dari kesehatan dan keselamatan kerja adalah jaminan kesehatan, fenomena yang terjadi adalah perbedaan jaminan kesehatan kerja dibedakan berdasarkan golongan kerja di perusahaanya. Pada dasarnya konsep distributive justice berkaitan erat tentang keadilan. Pekerja sosial hadir di setting industri untuk membantu menyelesaikan masalah yang terkait dengan kesejahteraan karyawan dan kemajuan perusahaan. Dengan intervensi yang tepat, hak-hak karyawan dalam perusahaan akan tetap terpenuhi dan perusahaan akan semakin berkembang.

Kata Kunci : Industrialisasi, Jaminan, Sistem Manajemen K3, Pekerjaan Sosial Industri, Distributive Justice
\end{abstract}

\section{PENDAHULUAN}

Pelaksanaan Kesehatan dan Keselamatan Kerja (K3) adalah salah satu bentuk upaya untuk menciptakan lingkungan kerja yang aman, sehat dan sejahtera, bebas dari kecelakaan kerja dan penyakit akibat kerja, serta bebas pencemaran lingkungan menuju peningkatan produktivitas sebagaimana diamanatkan dalam Undang-Undang No. 1 Tahun 1970 tentang Keselamatan Kerja. Seperti kita ketahui bahwa kecelakaan kerja bukan hanya menimbulkan korban jiwa maupun kerugian material bagi pekerja dan pengusaha tetapi dapat juga mengganggu proses produksi secara menyeluruh dan merusak lingkungan yang akhirnya berdampak kepada masyarakat luas. Karena itu, perlu dilakukan upaya yang nyata untuk mencegah dan mengurangi risiko terjadinya kecelakaan kerja dan penyakit akibat kerja secara maksimal. Apabila kita lakukan analisis secara mendalam maka kecelakaan, peledakan, kebakaran dan penyakit akibat kerja pada umumnya disebabkan karena tidak dijalankannya syarat-syarat K3 secara baik dan benar.

Suma'mur (1981) menjelaskan bahwa Keselamatan kerja adalah sarana utama untuk pencegaha kecelakaan, cacat dan kematian sebagai akibat kecelakaan kerja. Keselamatan kerja yang baik adalah pintu gerbang bagi keamanan tenaga kerja. Kecelakaan seain menjadi sebab hambatan langsung juga merupakan kerugian secara tidak langsung yaitu kerusakan mesin dan peralatan kerja, terhentinya proses produksi untuk beberapa saat kerusakan pada ingkungan kerja, dll. Kondisi pekerja yang baik dan merasa aman dengan pekerjaannya akan mempengaruhi produktivitas perusahaan atau industri tersebut. 
Pekerja yang sehat akan memberikan hasil yang maksimal dalam pekerjaannya dibandingkan dengan pekerja yang sakit. Oleh karenanya, keselamatan, keamanan, dan kesehatan pekerja harus diperhatikan bagi setiap pemilik usaha. Dengan memberikan jaminan atas keselamatan, keamanan, dan kesehatan kerja, setiap pekerja akan merasa bahwa dirinya memiliki jaminan atas semua resiko yang diakibatkan oleh pekerjaannya dan dapat membantu meningkatkan produktivitas perusahaan. Jaminan ini dapat berupa penyediaan alat pelindung diri seperti masker dan sarung tangan, atau berupa penataaan ruang kerja yang tepat.

Setiap perusahaan atau industri pasti memilki standar keselamatan, keamanan, dan kesehatan kerjanya sendiri - sendiri. Namun terkadang prosedur K3 yang telah diupayakan oleh pemilik perusahaan atau industri tersebut seringkali diabaikan oleh pekerjanya. Hal ini disebabkan para pekerja masih belum menyadari pentingnya mengikuti prosedur keselamatan, keamanan, dan kesehatan kerja. Padahal sebenarnya jika mengikuti prosedur K3 yang telah disediakan oleh perusahaan atau industri akan dapat meminimalisir resiko kecelakaan kerja.

PT Pertamina (persero) merupakan Badan Usaha Milik Negara (BUMN) yang bertugas mengelola penambangan minyak dan gas bumi di Indonesia. Produk yang dihasilkan oleh PT Pertamina (persero) adalah bahan bakar minyak, non-minyak, gas, pelumas dan petrokimia. Sebagai suatu badan perusahaan, PT Pertamina (persero) tentunya bertujuan mengusahakan keuntungan berdasarkan prinsip pengelolaan perseroan secara efektif, efisien dan memberikan kontribusi dalam meningkatkan kegiatan ekonomi untuk kesejahteraan dan kemakmuran rakyat. Dalam melaksanakan tujuan tersebut tentunya PT Pertamina (persero) mengoptimalkan seluruh sumber daya yang dimiliki dalam menghasilkan produk berkualitas tinggi. Kualitas produk yang dihasilkan tidak terlepas dari peranan sumber daya manusia (SDM) yang dimiliki perusahaan. Faktor-faktor produksi dalam perusahaan seperti modal, mesin, dan material dapat bermanfaat apabila telah diolah oleh SDM. Sebagai perusahaan yang memiliki banyak pekerja, PT PERTAMINA (Persero) memiliki kewajiban untuk menjamin keselamatan dan kesehatan pekerja dan bahkan meningkatkan kesejahteraan pekerjanya. Salah satu usaha yang dilakukan untuk menjamin keselamatan dan kesehatan kerja dengan membuat sistem manajemen K3 yang menguntungkan pekerja maupun perusahaan.

Sumber daya Manusia (SDM) di PT PERTAMINA (Persero) sebagai tenaga kerja tidak terlepas dari masalah-masalah yang berkaitan dengan keselamatan dan kesehatannya sewaktu bekerja. Oleh karena itu tenaga kerja perlu menjadi pusat perhatian, karena merupakan salah faktor pendukung utama keuntungan atau keberhasilan bisnis suatu perusahaan. Riset yang dilakukan badan dunia International Labour Organization (ILO) menghasilkan kesimpulan, setiap hari rata-rata 6.000 orang meninggal, setara dengan satu orang setiap 15 detik atau 2,2 juta orang per tahun akibat sakit atau kecelakaan yang berkaitan dengan pekerjaan. Secara keseluruhan kecelakaan di tempat kerja telah menewaskan 350.000 orang. Sisanya meninggal karena sakit yang diderita dalam pekerjaan seperti membongkar zat kimia beracun (ILO, 2003 dalam Suardi, 2007: 1).

Kegiatan PT Pertamina (persero) yang dapat menimbulkan bahaya dan resiko pekerja menurut Prosedur Tanggap Darurat P-001/SHE/05 Pertamina adalah semburan liar gas/minyak, kebakaran dan peledakan, tumpahan minyak dan kimia, terlepasnya gas $\mathrm{H} 2 \mathrm{~S}$, kondisi yang terkait georgrafis, politik dan social Indonesia berupa kerusuhan massa, ancaman bom, gempa bumi, tabrakan kapal, dan penyelamatan di laut (Prosedur Tanggap Darurat, 2005:4). Jika keadaan ini tidak mampu dikendalikan oleh PT Pertamina (persero), tenaga kerja mendapat kerugian berupa sakit, kecacatan, sampai kepada kematian yang tentunya akan berpengaruh dalam kehidupan sosial.

\section{PEMBAHASAN}

Menurut Kurniawan (2002), program K3 memperngaruhi kualitas hidup karyawan melalui jaminan keselamatan dan kesehatan karyawan yang merupakan bagian dari kesejahteraan karyawan dimana hal ini menjadi salah satu tujuan pembangunan Indonesia. Setiap perusahaan yang 
mempekerjakan tenaga kerja sebanyak 100 orang atau lebih dan/atau mengandung potensi bahaya yang ditimbulkan oleh karakteristik proses bahan produksi yang dapat mengakibatkan kecelakaan kerja seperti peledakan, kebakaran, pencemaran dan penyakit akibat kerja wajib menerapkan Sistem Manajemen K3. Hal ini di perkuat dengan UU No. 13 tahun 2003 tentang ketenagakerjaan yang menyatakan bahwa "setiap perusahaan wajib menerapkan system manajemen keselamatan dan kesehatan kerja yang terintegrasi dengan system manajemen perusahaan."

Sistem Manajemen Keselamatan dan Kesehatan Kerja (SMK3) meliputi struktur organisasi, perencanaan, tanggung jawab, pelaksanaan, prosedur, proses dan sumberdaya yang dibutuhkan bagi pengembangan, penerapan, pencapaian, pengkajian dan pemeliharaan kebijakan keselamatan dan kesehatan kerja dalam rangka pengendalian resiko yang berkaitan dengan kegiatan kerja guna terciptanya tempat kerja yang aman, efisien dan produktif.

Langkah awal untuk mengimplementasikan SMK3 adalah dengan menunjukkan komitmen serta kebijakan K3, yaitu suatu pernyataan tertulis yang ditandatangani oleh pengusaha dan atau pengurus yang memuat keseluruhan visi dan tujuan perusahaan, komitmen dan tekad melaksanakan K3, kerangka dan program kerja yang mencakup kegiatan perusahaan secara menyeluruh yang bersifat umum dan/atau operasional.

Ketika membicarakan tentang prosedur K3, maka akan terlihat keadilan distribusi dari program tersebut. Tentunya manajemen K3 haruslah berpihak kepada karyawan suatu perusahaan karena pada dasarnya program K3 ini merupakan hak yang di dapatkan karyawan atas pekerjaan yang telah dilakukanya. Keadilan distributif atau distributive justice seharusnya dapat digunakan sebagai pedoman untuk menentukan hak-hak yang akan diterima karyawan berdasarkan jasa yang telah diberikan kepada perusahaan. Sebagai seorang pekerja sosial yang memegang teguh prinsip keadilan sosial, maka keadilan distributif dari program K3 ini dapat dijadikan salah satu tempat praktik pekerjaan sosial untuk membantu karyawan mendapatkan hak-haknya terkait dengan kesehatan dan keselamatan kerja.

Dalam pelaksanaan keselamatan dan kesehatan kerja, tentunya ada tujuan yang ingin dicapai. Menurut Mangkunegara (2000) tujuan dari kesehatan dan keselamatan kerja sebenarnya telah terdapat di dalam UU No.1 tahun 1970 tentang kesehatan dan keselamatan kerja. Berikut adalah tujuan dari K3:

a. Agar setiap pegawai mendapat jaminan kesehatan dan keselamatan kerja baik secara fisik, sosial, dan psikologi.

b. Agar setiap perlengkapan dan peralatan kerja digunakan sebaik-baiknya dan se-efektif mungkin.

c. Agar semua hasil produksi di pelihara keamananya.

d. Agar adanya jaminan atas pemeliharaan dan meningkatan kesehatan gizi pegawai.

e. Agar meningkat kegairahan, keserasian, dan partisipasi kerja.

f. Agar terhindar dari gangguan kesehatan yang disebabkan oleh lingkungan atau kondisi kerja.

g. Agar setiap pegawai merasa aman dan terlingungi dalam bekerja.

Berangkat dari tujuan tersebut, pada dasarnya tujuan utama dari adanya kebijakan terkait dengan keselamatan dan kesehatan kerja adalah pemenuhan hak-hak karyawan yang bekerja di suatu perusahaan. Mulai dari pemenuhan hak keamanan, keselamatan, dan kesehatan dalam pekerjaanya yang akan menimbulkan perasaan nyaman bagi karyawan untuk bekerja secara maksimal di dalam perusahaan tersebut. Tentunya keselamatan dan kesehatan pekerja harus sangat diperhatikan oleh sebuah perusahaan karena Kartono (1971) menjelaskan bahwa :

"Di setiap perusahan, faktor yang terpenting adalah manusia. Karena dari manusia itulah bergantung perkembangan dan kemajuan organisasi, apabila manusia-manusia itu menjalankan tugasnya dengan baik, maka baik pula hasil yang dicapai perusahaan, sedangkan sebaliknya, apabila manusia itu menjalankan kewajibannya dengan acuh, maka perusahaan itu akan mundur atau ambruk sama sekali.” 
Penjelasan Kartono tersebut akan memperkuat bahwa untuk menjadikan perusahaan menjadi lebih baik pencapaianya dibutuhkan pekerja-pekerja yang menjalankan tugas dengan baik. Untuk menjalankan tugas dengan baik, maka pekerja membutuhkan salah satunya rasa aman dan sehat dalam bekerja dan hal ini dapat diwujudkan dengan sistem manajemen keselamatan dan kesehatan kerja yang baik.

Johnson (1984:261) mengklasifikasikan akibat-akibat industrialisasi yang bersifat negatif terhadap kesejahteraan manusia kedalam 5A, yaitu:

1. Alienation: perasaan keterasingan dari diri, keluarga dan kelompok sosial yang dapat menimbulkan apatis, marah, dan kecemasan.

2. Alcoholism atau Addiction: ketergantungan terhadap alkohol, obat-obat terlarang atau rokok yang dapat menurunkan produktifitas, merusak kesehatan pisik dan psikis, dan kehidupan sosial seseorang.

3. Absenteeism: kemangkiran kerja atau perilaku membolos kerja dikarenakan rendahnya motivasi pekerja, perasaan-perasaan malas, tidak berguna, tidak merasa memiliki perusahaan, atau sakit pisik dan psikis lainnya.

4. Accidents: kecelakaan kerja yang diakibatkan oleh menurunnya konsentrasi pekerja atau oleh lemahnya sistem keselamatan dan kesehatan lingkungan kerja.

5. Abuse: bentuk-bentuk perlakuan salah terhadap anak-anak atau pasangan dalam keluarga (istri/suami), seperti memukul dan menghardik secara berlebihan yang ditimbulkan oleh frustrasi, kebosanan dan kelelahan di tempat pekerjaannya.

Salah satu dari kelima akibat industrialisasi yang telah disebutkan Johnson membahas tentang kecelakaan kerja yang di akibatkan oleh sistem keselamatan dan kesehatan lingkungan kerja. Oleh karena itu pekerja sosial industri muncul sebagai jawaban atas dampak dari industrialisasi yang terjadi di dunia. Menurut Johnson (1984:263-264) ada tiga bidang tugas pekerja sosial yang bekerja di perusahaan:

1. Kebijakan, perencanaan dan administrasi. Bidang ini umumnya tidak melibatkan pelayanan sosial secara langsung. Sebagai contoh, perumusan kebijakan untuk peningkatan karir, pengadministrasian program-program tindakan afirmatif. pengkoordinasian program-program jaminan sosial dan bantuan sosial bagi para pekerja, atau perencanaan kegiatan-kegiatan sosial dalam departemen-departemen perusahaan.

2. Praktik langsung dengan individu, keluarga dan populasi khusus. Tugas pekerja sosial dalam bidang ini meliputi intervensi krisis (crisis intervention), asesmen (penggalian) masalah-masalah personal dan pelayanan rujukan, pemberian konseling bagi pecandu alkohol dan obat-obatan terlarang, pelayanan dan perawatan sosial bagi anak-anak pekerja dalam perusahaan atau organisasi serikat kerja, dan pemberian konseling bagi para pensiunan atau pekerja yang menjelang pensiun.

3. Praktik yang mengkombinasikan pelayanan sosial langsung dan perumusan kebijakan sosial bagi perusahaan.

Pekerjaan sosial adalah profesi pertolongan kamanusiaan yang tujuan utamanya adalah membantu keberfungsian sosial individu, keluarga dan masyarakat dalam melaksanakan peran-peran sosialnya (Siporin, 1975; Morales dan Sheafor, 1989; Suharto, 1997). Para pekerja sosial memiliki seperangkat pengetahuan, keterampilan dan nilai-nilai pertolongan profesional yang diperoleh melalui pendidikan (perguruan tinggi). Secara konvensional, pekerjaan sosial biasanya dipandang sebagai profesi yang menangani permasalahan kesejahteraan sosial baik pada setting lembaga maupun masyarakat. Dalam setting lembaga, pekerja sosial biasanya bekerja pada institusi-institusi pelayanan sosial, seperti lembaga rehabilitasi sosial, pengasuhan anak, perawatan orang tua, 
penanganan korban narkoba dll. Dalam setting masyarakat, pekerja sosial menangani permasalahan sosial yang berkaitan dengan pembangunan lokal (pedesaan dan perkotaan), pengentasan kemiskinan atau perancangan proyek-proyek pengembangan masyarakat (community development)

Sejalan dengan perkembangan masyarakat yang semakin kompleks, sasaran, bidang garapan dan intervensi profesi pekerjaan sosial juga semakin luas. Globalisasi dan industrialisasi membuka kesempatan bagi pekerjaan sosial untuk terlibat dalam bidang yang relatif baru, yakni dunia industri. Seperti halnya pekerja sosial medik (medical social worker) yang bekerja di rumah sakit, para pekerja sosial industri (industrial social worker) ini bekerja di perusahaan-perusahaan, baik negeri maupun swasta, untuk menangani kesejahteraan, kesehatan dan keselamatan kerja, relasi buruh dan majikan, atau perekrutan dan pengembangan pegawai.

Salah satu tujuan dari hadirnya profesi pekerjaan sosial tidak lain untuk membantu mewujudkan keadilan sosial bagi seluruh klien. Salah satu prinsip keadilan distributif yang disampaikan John Rawl (1999), sebagai berikut:

the different principle" dan "the principle of (fair) equality of opportunity", merupakan "prinsip perbedaan obyektif", artinya prinsip kedua tersebut menjamin terwujudnya proporsionalitas pertukaran hak dan kewajiban para pihak, sehingga secara wajar (obyektif) diterima adanya perbedaan pertukaran asalkan memenuhi syarat good faith and fairness (redelijkheid en billijkheid). “"

Pada dasarnya Rawls menegaskan bahwa setiap orang memiliki hak atas kewajibanya secara proporsional. Pertukaran hak dan kewajiban haruslah sesuai dan objektif tanpa disamaratakan. Keadilan yang diusung John Rawls lebih menekankan kepada setiap orang memiliki hak. Namun, hak-hak yang dia dapat akan seimbang dengan kewajiban yang dia lakukan.

Menurut (Van den Bos : 1999). Keadilan distributif terletak pada implementasi peraturan. Untuk menilai distribusi adil atau tidak, dapat dilihat dari tegaknya peraturan yang diterapkan. Bila peraturan yang disepakati tidak dijalankan sama sekali atau dijalankan sebagian, keadilan distribusi tidak tercapai. Oleh karena itu tegaknya peraturan yang telah dibuat dapat dijadikan indikator dari tercapainya keadilan distributif.

\section{KESIMPULAN}

Dunia industri kini sedang menggali manfaat-manfaat positif dari adanya pelayanan sosial tersebut, baik tehadap aspek finansial maupun relasi sosial dengan para pekerja dan masyarakat. Di AS, sekitar setengah dari perusahaan-perusahaan terbesar kini memiliki apa yang dinamakan Employee Assistance Programs (EAPs), program-program bantuan kesejahteraan sosial bagi para pekerja dan keluarganya. Dalam upaya menurunkan tingkat kemangkiran kerja saja, peusahaanperusahaan sanggup mengeluarkan biaya-biaya tambahan untuk program-program sosial dan penanggulangan alkoholisme. Pelayanan sosial seperti ini seringkali disebut sebagai "kontrak kemanusiaan" (human contract) atau "wajah manusiawi industri" (the human face of industry) (Johnson, 1984).

Selain program-program unggulan yang dikeluarkan oleh perusahaan-perusahaan tersebut, jaminan-jaminan perusahaan kepada pekerjanya semakin diperbaiki. Didasari prinsip teori keadilan distributive yang diusung John Rawls, maka perbedaan jaminan kesehatan berdasarkan golongan kerja yang diterapkan di PT PERTAMINA (PERSERO) merupakan sebuah keadilan distributif. Hal ini akan diperkuat jika implementasinya berjalan dengan baik sesuai dengan pendapat Van den Bos (1999) yang menyatakan jika implementasi berjalan dengan baik dan disepakati bersama, maka keadilan distributif sudah tercapai.

pekerjaan sosial biasanya dipandang sebagai profesi yang menangani permasalahan kesejahteraan sosial baik pada setting lembaga maupun masyarakat. Dalam setting pekerjaan sosial industri, pekerja sosial diharapkan mampu menangani kebutuhan-kebutuhan kemanusiaan dan sosial 
di dunia kerja melalui berbagai intervnsi dan penerapan metoda pertolongan yang bertujuan untuk memelihara adaptasi optimal antara individu dan lingkunganya, terutam lingkungan kerja. Jadi system manajemen kesehatan dan keselamatan kerja juga menjadi salah satu bidang garapan seorang pekerja sosial yang berada di setting industri. Tujuan dari hadirnya pekerja sosial di bidang industri akan kembali kepada bagaimana pekerja sosial mampu membantu pengorganisasian perusahaan dan pemenuhan hak-hak dari para pekerjanya untuk mencapai keadilan distributive.

\section{DAFTAR RUJUKAN}

Bambang, Guntur ; 2002 ; Kebijakan Kesehatan dan Keselamatan Kerja Depkes ; Jakarta : Universitas Indonesia

Dassler, Gary; 1993. Manajemen Personalia. Jakarta: Pustaka Binawan Pressindo.

Googins, Bradley dan Joline Godfrey. 1987. Occupational Social Work. New Jersey: Prentice-Hall, Inc.

Johnson, Wayne (1984), The Social Services: An introduction, New York: FE Peacock.

Kartono; 1971 ; Unsur Manusia dalam Perusahaan Modern; Jakarta ; Pradya Paramita

Kurniawan, Yudhi; 2002. Sistem Manajemen Pelaksanaan Manajemen K3 dalam perusahaan; Depok. Universitas Indonesia

K. Suma'mur ; 1981 ; Keselamatan Kerja dan pencegahan kecelakaan; Jakarta ; Gunung Agung Mangkunegara, Anwar ; 2000 ; Manajemen SDM Perusahaan ; Bandung ; PT Remaja Rosdakarya Rawls, John ; 1999 ; A Theory of Justice ; Boston ; Harvard University Press.

Suharto, Edi. 2009. Pekerjaan Sosial di Dunia Industri: Memperkuat Tanggungjawab Sosial Perusahaan (Corporate Social Responsibility). Bandung: Alfabeta

Wibhawa, Budi, dkk. 2010. Dasar-Dasar Pekerjaan Sosial. Bandung: Widya Padjadjaran 